\title{
Effect of hypnotherapy on smoking cessation among secondary school students
}

\author{
Noha Ahmed Mohamed *, Seham Mohamed EIMwafie \\ Faculty of Nursing, Beni-Suef University, Beni Suef, Egypt
}

Received: August 9, 2014

Accepted: November 9, 2014 Online Published: November 27, 2014

DOI: $10.5430 /$ jnep.v5n2p67

URL: http://dx.doi.org/10.5430/jnep.v5n2p67

\begin{abstract}
Background: Hypnotherapy is widely promoted as a method for aiding smoking cessation. It is proposed to act on underlying impulses to weaken the desire to smoke or strengthen the will to stop. The aim of this study was to examine the effectiveness of hypnotherapy on smoking cessation among secondary school students.

Method: A random sample of 59 male smokers was selected from two governmental secondary schools. Design: A quasiexperimental design was used. Tools: Data were collected using; A- an Interview Questionnaire included; I- smoking assessment tool to determine the smoking rate among males students. II-Characteristics of studied students regarding smoking pattern. IIISmoking Cessation Questionnaire. B- Wisconsin smoking withdrawal scale. The hypnotherapy was implemented after assessing the rate of male smokers, the researchers trained the students in practicing self hypnosis, and asked them to practice it at home and to document the frequency of daily smoked packs for nine weeks.

Results: The present study findings indicated that the rate of male smokers among secondary school students in Beni-Suef city was $52.4 \%$, about two third of studied students $(65.4 \%)$ stopped smoking after nine weeks of practicing hypnosis and the percentage of smoked packs of cigarettes/ day decreased after implementing the program.

Conclusion: The present study findings showed that hypnotherapy has a therapeutic effectiveness in achieving a high rate of smoking cessation among secondary school students. There was a highly significant difference in total score of smoking withdrawal index before and after intervention. Recommendation: Community and school education programs should include sessions on quitting smoking, implementing school-based interventions in combination with antitobacco mass media campaigns.
\end{abstract}

Key Words: Secondary school students, Hypnotherapy, Smoking cessation

\section{Introduction}

The aim of hypnotherapy in smoking cessation is to decrease the desire to smoke or strengthen the will to stop smoking. The patient is guided by the hypnotherapist to respond to suggestions for changes in the smoking experience. Treatment success can be influenced by the therapeutic relationship or the hypnotisability of the patient. ${ }^{[1]}$ Worldwide, Smoking epidemic is a major public health problem, more than half of those who addicted to it losses their life, it resulting in high rates of morbidity and mortality. Smoking prevalence is a public health problem in Egypt. Egypt's ranking as one of the countries that bears the highest burden of tobacco use worldwide combined with lack of data on many tobacco-related elements, as well as emergence of new groups of tobacco users and new forms of tobacco use. ${ }^{[2]}$ Smoking prevalence among adult males aged 15 Egypt.

Published by Sciedu Press 
years and over in Egypt was 39.7\%. Smoking harms nearly every organ of the body, causing many diseases and affecting the health of smokers in general. ${ }^{[3]}$ Quitting smoking has immediate as well as long-term benefits. ${ }^{[4]}$

Cigarette smoking cause serious health problems among youth. Compared with adults, adolescents appear to display evidence of nicotine addiction at much lower levels of consumption, making quit attempts potentially more difficult for them. Nicotine, is a highly addictive drug, causes many to continue smoking well into adulthood, often with deadly consequences. Many young smokers have strong expectations of discontinuing use in the near future, but relatively few are able to do so. Most of these young people never considered the long-term health consequences associated with tobacco use when they started smokinG ${ }^{[4]}$ In fact, nearly 9 out of 10 smokers start smoking by age 18, and $99 \%$ start by age 26 . Today, one out of four high school seniors and one out of three young adults under age 26 are smokers. On any given day, more than 2.500 youth and young adults who have been occasional smokers will become regular smokers. And at least a third of these replacement smokers will die early from smoking. ${ }^{[5]}$

Many teens and young adults plan to quit using tobacco after a few years but find out too late how powerfully addictive nicotine can be. Like heroin and cocaine, nicotine acts on the brain and creates feelings of pleasure or satisfaction. Many teens feel dependent on tobacco after using it for only a short time because young brains are still developing. Smokers who quit before age 30 will undo much of the health damage caused by tobacco use. Despite the demonstrated efficacy of pharmacological smoking cessation treatments, many smokers are unwilling to use them; however, they are inclined to try alternative methods. Hypnotherapy has been recognized as a therapeutic tool by professional medical groups in a number of countries for many years, and can be powerful for changing patterns of behavior. ${ }^{[6]}$

Hypnosis has a higher success ratio in smoking cessation than any of the other physical means available on the market today (such as the gums, pills and patches) and it requires as little as one or two sessions of approximately 3040 minutes. The reason for this is that hypnosis dealing with the strong subconscious mind, where all the physical means are just dealing with the conscious mind and the subconscious mind does not understand the difference between an imagined memory and a real memory. Hypnosis is a relaxing, naturally occurring state of mind which happens to us every day. Each time we read a captivating novel, float off in a daydream or see an engrossing movie we are in a natural state of hypnosis. Hypnosis deals directly with the subconscious mind, which is the part of mind that carries out habituated patterns of behavior, including smoking. It's the subconscious that directs the body to feel the urge for a cigarette. Subconscious mind knows exactly when it's time to light up another cigarette and it reminds us right on cue.
So the key to actually quitting smoking is to convince our subconscious mind that it's time to make a change. ${ }^{[7]}$ It is proposed to act on underlying impulses to weaken the desire to smoke or strengthen the will to stop. ${ }^{[8]}$

Nurses have a significant role in planning, implementing, and evaluating effective smoking cessation treatments and providing health education for youth and adult smokers about serious effects on human health. It is reasonable to expect that more smokers will quit successfully if nurses deliver evidence-based smoking cessation interventions. Nurses can provide effective advice for people stopping smoking. Nurses as a member of professional medical groups can use hypnotherapy as a therapeutic tool that is powerful for changing patterns of behavior. Trained nurses on hypnosis can employ hypnotic strategies that invite smokers to imaginatively associate cigarettes with unpleasant sensations such as bus fumes and dry mouth or negative outcomes such as cancer. They also use suggestions to encourage smokers to believe that they will lose the desire to smoke and cope well during withdrawal. ${ }^{[9]}$

The nursing profession has a long history of viewing and caring for individuals in a holistic manner. RNs recognize cultural, psychosocial, and spiritual needs that can impact upon health care practices, choices and preferences for treatment or non-intervention. Inherent in the nurse's role is the ability to assess, intervene and evaluate preventive, supportive, and restorative functions of a patient's physical, emotional, mental and spiritual domains. ${ }^{[9]}$

\subsection{Significance of the study}

The magnitude of the smoking problem in adolescents is large enough to be considered a warning of an impending epidemic. Behavior modification of adolescents should be carried out on a large scale. Multi-centered studies with a homogenous population would be appropriate to measure the effectiveness of intervention strategies. ${ }^{[1]}$ Moreover smoking is a pediatric epidemic around the world as well as in Egypt. Nearly all smoking begins in childhood and adolescence. ${ }^{[12]}$ Therefore preventing smoking among young people is critical to ending the epi-demic of tobacco use. If young people don't start using tobacco by age 26, they almost certainly will never start. ${ }^{[4,13]}$ Youth smoking cessation programs are necessary to target those adolescents who are considering quitting smoking. These approaches to reducing youth tobacco use require a strong, comprehensive tobacco prevention and control program and the dedication of policymakers and community members. ${ }^{[14]}$

\subsection{Aim of the study}

The aim of this study was to examine the effectiveness of hypnotherapy on smoking cessation among secondary school students in Beni-Suef city. 


\subsection{Research hypothesis}

This study was conducted to test the following hypothesis: Hypnotherapy has a therapeutic effect in achieving a high rate of smoking cessation among secondary school students.

\section{Methodology}

\subsection{Research design}

A quasi-experimental design with pre-post assessment was used in this study.

\subsection{The research setting}

Two secondary schools were selected randomly from two educational zones available in Beni-Suef City.

\subsection{Study subjects}

Subjects in this study were all students who follow the criteria (59 male students).

\subsection{Inclusion criteria}

- Accepted to participate in the study.

- Smoking at least 5 cigarettes per day.

- Not using other cessation methods.

- Willing to quit smoking.

- Not have a history of psychotic disorders.

- Not use stimulating medications.

- Male students of the 3rd grade.

- Aging from 18-20 years.

\subsection{Tools of data collection}

A- Questionnaire was used for data collection, it included two parts:

1)- Smoking Assessment Questionnaire to assess the smoking rate among secondary school students adopted from The American School of Hypnosis. ${ }^{[6]}$ included questions about name, age, phone number, are you smoker, how many cigarettes/ day, are you want to quit, if yes, are you prefer to try quitting by non-pharmacological methods, are you using any cessation methods, are you having any history of psychotic disorders, are you using stimulating medications.

2)- An interview questionnaire form adopted from The American School of Hypnosis, ${ }^{[6]}$ to collect data about characteristics of studying students regarding pattern of smoking included questions about; duration of smoking in years, number of smoked packed/day, smoking household members, reasons for quitting smoking, and number of trails to quit smoking, longest duration of quitting smoking.

3)- Smoking Cessation Questionnaire \& follow-up sheet to determine the number of packs smoked daily based on the

Published by Sciedu Press tool of McKINIEY Health Center, ${ }^{[15]}$ which included questions such as "Things willing to change for quitting", "Supporting sources for support to quit smoking, Factors helping to quit smoking", etc.

B- Wisconsin smoking withdrawal scale ${ }^{[15]}$ which included 28- item sorted by seven subscales about anger, anxiety, concentration, craving, hunger, sadness and sleep. The response was on a 5-point Likert scale ranging from "strongly disagree $=0$ " to "strongly agree $=4$ ". For all items except items number ${ }^{[1,2,4,10,17,22,24]}$ these items are reverse scored.

\subsection{Field work}

Official permission was obtained first from the security department, then the Ministry of Education, and from the directors of educational zones. Based on their approvals, permission was taken from the directors of selected schools to collect the data. The researcher started by explaining the purpose of the study briefly to students. Participants were informed about their right to withdraw from the study at any time without giving any reason. Data were considered confidential and not be used outside this study without the patient's approval. The researcher phone number and all possible communicating methods (as e-mail) were identified to the participants to return at any time for any explanation.

\subsection{Validity and reliability}

Tool validity test was done through five panels of expertise (they are Faculty members of community health nursing and pediatric nursing departments).

The internal consistency of the instrument has been tested using Cronbach's alpha coefficient. Cronbach's alpha for the whole questionnaire was 0.86 . Cronbach's alpha coefficients were also calculated of each of the subscales.

\subsection{Pilot study}

A pilot study was carried out on $10 \%$ of the sample size to test the content of the questionnaire as well as to estimate the time needed for data collection and the necessary modifications was done. Those who shared in the pilot study were excluded from the study sample.

\subsection{Ethical considerations}

Oral consent was taken from students included in the study, they were informed that the data collected will be used for the research only, and confident manner is assured.

\subsection{Procedure}

- Data collection was carried out over a period of 12 weeks.

- Official permission was obtained first from the Security Department, then the Ministry of Education, and from the directors of educational zones. Based on 
their approvals, permission was taken from the directors of the selected schools to collect the data.

- The researcher started by explaining the purpose of the study briefly to the students.

- The researchers started recruiting the sample by using survey to determine the rate of male smokers.

- Eligible students were met, and were invited to participate after explaining to them the purpose of the study and its procedure. Those who gave their consent to participate were interviewed using the questionnaire form, including the smoking withdrawal scale.

- The researchers trained the students in practicing self hypnosis, and asked them to practice it at home and to document the frequency of daily smoked packs for nine weeks.

\subsection{Technique of hypnosis}

The researchers followed the recommendations of Barnes et al. ${ }^{[17]}$ and Abbot et al. ${ }^{[18]}$ when designing the study; however, no standardized protocol existed for hypnotic interventions in smoking cessation. There are some elements that are common to most interventions, such as those named by Spiegel et al. (e.g., that a body is entitled to protection from smoke), but there are many degrees of freedom in the implementation of hypnotic procedures that may affect the outcomes of hypnotic intervention. ${ }^{[19]}$ Spiegel's method acknowledges that there are some unarguable pleasures to smoking. Instead, he encourages hypnotized smokers to concentrate on three ideas: 1) smoking is a poison for your body; 2) you need your body to live; and 3) to the extent that you want to live, you owe your body respect and protection. The researcher taught the students self-hypnosis and encouraged them to repeat these ideas every one to two hours and any time they experience an urge to smoke.

The students asked to follow this technique steps and then they practiced at least once /day every day for nine weeks and they met every week to ensure that they practicing self hypnosis correctly.

(1) First, find a quiet area in your home where you won't be distracted. Unplug your phone, turn off your computer and minimize as much noise as possible.

(2) Sit in a comfortable area and close your eyes. Start to focus on your breathing, and visualize all of your muscles relaxing as you breathe in and out while taking a deep breath.

(3) Once you're suitably relaxed, it's time to say a few smoke-free affirmations out loud such as: "My health is worth more than a cigarette"; "I am powerful enough to stop smoking for good"; "I know that being smoke free will make be happier and healthier"; and "I am stronger than nicotine... etc......."

(4) Repeat these affirmations over and over again. Do this for approximately five to ten minutes at a time.
(5) think of yourself in the following way ... I am a nonsmoker ... I have stopped smoking ... and I will never smoke again ... and as a nonsmoker I have the ability to be around other people who smoke ... I have the ability to enjoy life as a nonsmoker ... everything I do ... from this moment on ... is better as a nonsmoker ....You feel so much better ... As a nonsmoker ... healthier ... breathe easier ... enjoy life more ...more confidence....... etc.....

\subsection{Limitations}

The total number of male smoker students who fulfilled the eligibility criteria was 59 and they dropped to 52 during the follow-up period, the other 7 decided to not continue and the researcher respected their decisions.

\subsection{Statistical analysis}

The collected data were organized, tabulated and statistically analyzed using Statistical Package of Social Studies (SPSS) version 19. Variables were categorical and were presented as number and percentages. Differences between categories before and after intervention and at different periods of follow up were statistically analyzed using Wilcoxon singed ranks test. Total smoking index score was calculated by summation of the score of the 27 smoking index questions. The total scores before and after intervention was presented as range, mean and standard deviation. The difference between total smoking index score before and after intervention was performed using paired t test. The level of significance was adopted at $p<.05$.

\section{Results}

The rate of male smokers among secondary school students in Beni-Suef city was $52.4 \%$ and $47.6 \%$ was nonsmokers (see Figure 1).

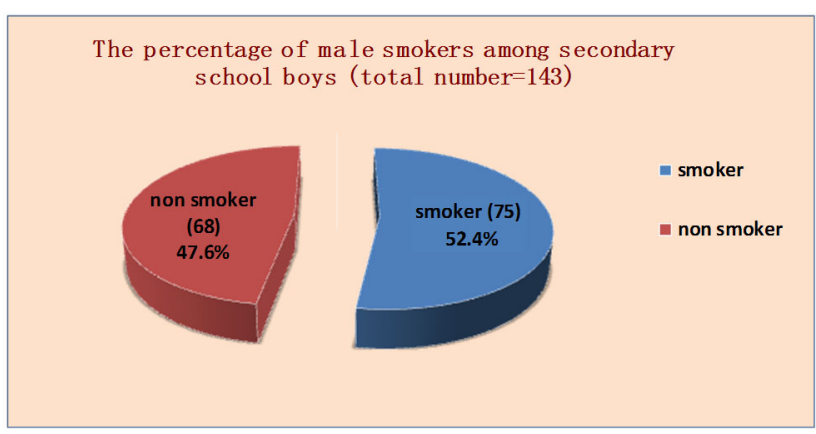

Figure 1: Rate of male smokers among secondary school students $(n=143)$

One third $(32.7 \%)$ of studied students started smoking since one year while $23.0 \%$ started from four years and more, and $28.8 \%$ smoked 2-3 packs/day, half of them were living 
with a family member who smoke, and they reported that ing while the rest tried once or more, more than half of them they wanted to stop smoking to preserve health and money $(55.8 \%)$ stopped smoking for less than one week and only $(57.7 \%, 50.0 \%$ respectively) while $63.5 \%$ wanted to be free $\quad(1.9 \%)$ quitted for a period of one to three years (see Table from smoking, and $26.9 \%$ of them never tried to stop smok- 1 ).

Table 1: Characteristics of studied students regarding smoking pattern $(\mathrm{n}=52)$

\begin{tabular}{|c|c|c|}
\hline Variables & $\bar{n}$ & $\%$ \\
\hline \multicolumn{3}{|l|}{ Duration of smoking in years: } \\
\hline One year & 17 & 32.7 \\
\hline Two years & 12 & 23.1 \\
\hline Three years & 11 & 21.2 \\
\hline Four and more & 12 & 23.0 \\
\hline \multicolumn{3}{|c|}{ Number of smoked packed/day: } \\
\hline From 5 cigarettes $\leq 1 / 2$ pack & 7 & 13.5 \\
\hline$>1 / 2-1$ pack & 10 & 19.2 \\
\hline $1-1 \frac{1}{2}$ pack & 11 & 21.2 \\
\hline 2-3 pack & 15 & 28.8 \\
\hline $3+$ pack & 9 & 17.3 \\
\hline \multicolumn{3}{|c|}{ Smoking household members: } \\
\hline No one & 13 & 25.0 \\
\hline One member & 12 & 23.1 \\
\hline Two members & 14 & 26.9 \\
\hline Three or more & 13 & 25.0 \\
\hline \multicolumn{3}{|c|}{ Reasons for quitting smoking:* } \\
\hline Preserve health & 30 & 57.7 \\
\hline Preserve money & 26 & 50.0 \\
\hline Satisfy family & 12 & 23.1 \\
\hline Save time & 17 & 32.7 \\
\hline Avoid bad breath & 10 & 19.2 \\
\hline To be smoke free & 33 & 63.5 \\
\hline For social acceptability & 9 & 17.3 \\
\hline \multicolumn{3}{|c|}{ Number of trails to quit smoking: } \\
\hline Never & 14 & 26.9 \\
\hline Once & 19 & 36.5 \\
\hline Twice & 9 & 17.3 \\
\hline Three times & 6 & 11.5 \\
\hline Four and five times & 4 & 7.8 \\
\hline \multicolumn{3}{|c|}{ Longest duration of quitting smoking: } \\
\hline$<1$ week & 29 & 55.8 \\
\hline 2-3 weeks & 16 & 30.8 \\
\hline $1-6$ months & 5 & 9.6 \\
\hline 7-11 months & 1 & 1.9 \\
\hline $1-3$ years & 1 & 1.9 \\
\hline
\end{tabular}

*More than one reason was reported

More than half of the studied students ready to change many things in order to stop smoking such as personal habits, lifestyle, and exercise routinely $(57.7 \%, 50.0 \%$, and $63.5 \%$ respectively). They reported that the family followed by friends $(53.8 \%, 25.0 \%$ respectively) considered to be support system, and strong willpower and desire are factors were helping them to stop smoking $(71.0 \%, 61.5 \%$ respectively), but they mentioned many fears as failure, mood changes, poor self esteem, or loss of control $(53.8 \%, 38.5 \%$,
$32.5 \%, 30.8 \%$ respectively). Most of them were dealing with stressors through prayers $(71.2 \%)$ while only $3.8 \%$ were using hypnosis as a method of relieving stress (see Table 2).

There was a highly significant difference in total score of smoking index before and after intervention, it was ranged from 69-93 before intervention compared with 12-41 after intervention with mean of $82.96+6.26$ 93before intervention compared with $25.08+5.30$ after intervention (see Table 3). 
Table 2: Distribution of studied students by factors associated with quitting smoking

\begin{tabular}{|c|c|c|}
\hline Variables & $\bar{n}$ & $\%$ \\
\hline \multicolumn{3}{|c|}{ Things willing to change for quitting:* } \\
\hline Any thing & 18 & 34.6 \\
\hline Personal habits & 30 & 57.7 \\
\hline Life style & 26 & 50.0 \\
\hline Diet & 13 & 25.0 \\
\hline Exercise routine & 33 & 63.5 \\
\hline \multicolumn{3}{|l|}{ Sources for support to quit smoking: } \\
\hline Family & 28 & 53.8 \\
\hline Friends & 13 & 25.0 \\
\hline Every body & 8 & 15.4 \\
\hline Others & 2 & 3.8 \\
\hline None & 1 & 1.9 \\
\hline \multicolumn{3}{|l|}{ Factors helping to quit smoking:* } \\
\hline Strong willpower & 40 & 77.0 \\
\hline Desire to be smoke free & 32 & 61.5 \\
\hline Presence of effective support & 18 & 34.6 \\
\hline Changing attitude & 16 & 30.8 \\
\hline Support by quitting friend/relative & 13 & 25.0 \\
\hline Stressor relievers & 12 & 23.1 \\
\hline \multicolumn{3}{|c|}{ Fears associated with efforts to quit smoking:* } \\
\hline Failure & 28 & 53.8 \\
\hline Mood changes & 20 & 38.5 \\
\hline Poor self esteem & 17 & 32.7 \\
\hline Loss of control & 16 & 30.8 \\
\hline Becoming tense/nervous & 10 & 19.2 \\
\hline Weight gain & 7 & 13.5 \\
\hline \multicolumn{3}{|c|}{ Major stressors that lead to smoking:* } \\
\hline Money & 30 & 57.7 \\
\hline Family & 18 & 34.6 \\
\hline One's health & 15 & 28.8 \\
\hline School & 11 & 21.2 \\
\hline Time & 7 & 13.5 \\
\hline Relationships & 7 & 13.5 \\
\hline Family health & 7 & 13.5 \\
\hline None & 3 & 5.8 \\
\hline \multicolumn{3}{|l|}{ Methods dealing with stressors:* } \\
\hline Prayers & 37 & 71.2 \\
\hline Hobbies & 15 & 28.8 \\
\hline Reading & 12 & 23.1 \\
\hline Relaxation & 8 & 15.4 \\
\hline Exercise & 8 & 15.4 \\
\hline Sleep & 7 & 13.5 \\
\hline Eating & 7 & 13.5 \\
\hline Listening to music & 6 & 11.5 \\
\hline Keep self busy & 4 & 7.7 \\
\hline Hypnosis & 2 & 3.8 \\
\hline None & 5 & 9.6 \\
\hline
\end{tabular}

*More than one reason was reported

Table 3: Comparison of total score of smoking index before and after intervention

\begin{tabular}{lllll}
\hline Smoking index total score & Range & Mean \pm SD & T & P \\
\hline Before intervention & $69-93$ & $82.96 \pm 6.26$ & 42.957 & $.001^{*}$ \\
After intervention & $12-41$ & $25.08 \pm 5.30$ & & \\
\hline
\end{tabular}

*Significant

There were statistically significant differences between number of smoked packs/ day and time of measurement at different periods of follow up at the weeks $2 \mathrm{nd}$, 3rd, 8th, and 9 th week. The results clarified that the rate of quit- ting among studied students were $65.4 \%$, and the number of smoked packs/day decreased with time of practicing hypnosis (see Table 4). 
Table 4: Number of smoked packs at different periods of follow up

\begin{tabular}{|c|c|c|c|c|c|c|c|c|c|c|c|c|c|c|}
\hline \multirow{3}{*}{$\begin{array}{l}\text { Time of } \\
\text { measurement }\end{array}$} & \multicolumn{12}{|c|}{ Number of smoked packs } & \multirow{3}{*}{$\mathbf{Z}$} & \multirow{3}{*}{$p$} \\
\hline & \multicolumn{2}{|c|}{ Totally quitting } & \multicolumn{2}{|c|}{5 cigarettes $\leq 1 / 2$ pack } & \multicolumn{2}{|c|}{$>1 / 2-1$ pack } & \multicolumn{2}{|c|}{$>1-1 \frac{1}{2}$ pack } & \multicolumn{2}{|c|}{$<2-3$ pack } & \multicolumn{2}{|c|}{$>3$ pack } & & \\
\hline & $\mathbf{N}$ & $\%$ & $\mathbf{N}$ & $\%$ & 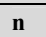 & $\%$ & $\mathbf{N}$ & $\%$ & $\mathbf{n}$ & $\%$ & $\mathbf{n}$ & $\%$ & & \\
\hline $1^{\text {st }}$ week & 0 & 0.0 & 8 & 15.4 & 10 & 19.2 & 11 & 21.2 & 14 & 26.9 & 9 & 17.3 & --- & ----- \\
\hline $2^{\text {nd }}$ week & 0 & 0.0 & 18 & 34.6 & 13 & 25.0 & 7 & 13.5 & 11 & 21.2 & 3 & 5.8 & 4.725 & .001 \\
\hline $3^{\text {rd }}$ week & 1 & 1.9 & 19 & 36.5 & 13 & 25.0 & 8 & 15.4 & 8 & 15.4 & 3 & 5.8 & 4.384 & .001 \\
\hline $4^{\text {th }}$ week & 6 & 11.5 & 18 & 34.6 & 13 & 25.0 & 11 & 21.2 & 4 & 7.7 & 0 & 0.0 & 2.853 & .004 \\
\hline $5^{\text {th }}$ week & 12 & 23.1 & 14 & 26.9 & 13 & 25.0 & 11 & 21.2 & 1 & 1.9 & 1 & 1.9 & 0.475 & .635 \\
\hline $6^{\text {th }}$ week & 19 & 36.5 & 15 & 28.8 & 13 & 25.0 & 4 & 7.7 & 1 & 1.9 & 0 & 0.0 & 1.080 & .280 \\
\hline $7^{\text {th }}$ week & 21 & 40.4 & 20 & 38.5 & 9 & 17.3 & 2 & 3.8 & 0 & 0.0 & 0 & 0.0 & 1.309 & .190 \\
\hline $8^{\text {th }}$ week & 28 & 53.8 & 13 & 25.0 & 10 & 19.2 & 1 & 1.9 & 0 & 0.0 & 0 & 0.0 & 2.914 & .004 \\
\hline $9^{\text {th }}$ week & 34 & 65.4 & 9 & 17.3 & 8 & 15.4 & 1 & 1.9 & 0 & 0.0 & 0 & 0.0 & 4.150 & .001 \\
\hline
\end{tabular}

There was an improvement in the withdrawal symptoms af- anxiety item (worry about my problems), two fifth (42.3\%) ter the program. Statistically significant differences were of studied students were worry about their problems before found regarding all items of smoking withdrawal index intervention compared with quarter $(25.0 \%)$ of them after (anger, anxiety, concentration, craving, hunger, sadness, and intervention (see Table 5).

sleep) before and after intervention except one sub item of

Table 5: Distribution of studied students by smoking withdrawal index before and after intervention

\begin{tabular}{|c|c|c|c|c|c|c|c|c|c|c|c|c|c|c|}
\hline \multirow{3}{*}{ Variables } & \multicolumn{6}{|c|}{ Before intervention } & \multicolumn{6}{|c|}{ After intervention } & \multirow{3}{*}{$\mathbf{Z}$} & \multirow{3}{*}{$\boldsymbol{P}$} \\
\hline & \multicolumn{2}{|c|}{$\begin{array}{l}\text { Strongly } \\
\text { disagree/Disagree }\end{array}$} & \multicolumn{2}{|c|}{ Neutral } & \multicolumn{2}{|c|}{$\begin{array}{l}\text { Agree/ } \\
\text { strongly agree }\end{array}$} & \multicolumn{2}{|c|}{$\begin{array}{l}\text { Strongly } \\
\text { disagree/disagree }\end{array}$} & \multicolumn{2}{|c|}{ Neutral } & \multicolumn{2}{|c|}{$\begin{array}{l}\text { Agree/ } \\
\text { strongly agree }\end{array}$} & & \\
\hline & No. & $\%$ & No. & $\%$ & No. & $\%$ & No. & $\%$ & No. & $\%$ & No. & $\%$ & & \\
\hline \multicolumn{15}{|l|}{ Anger } \\
\hline Irritable and easy angered & 0 & 0.0 & 1 & 1.9 & 51 & 98.1 & 42 & 92.3 & 4 & 7.7 & 0 & 0.0 & 6.505 & .001 \\
\hline Bothered by negative mode & 0 & 0.0 & 3 & 5.8 & 49 & 94.2 & 49 & 94.2 & 3 & 5.8 & 0 & 0.0 & 6.334 & .001 \\
\hline Frustrated & 1 & 1.9 & 3 & 5.8 & 48 & 92.3 & 50 & 96.2 & 2 & 3.8 & 0 & 0.0 & 6.397 & .001 \\
\hline \multicolumn{15}{|l|}{ Anxiety } \\
\hline Tense or anxious & 0 & 0.0 & 1 & 1.9 & 51 & 98.1 & 45 & 86.5 & 7 & 13.5 & 0 & 0.0 & 6.452 & .001 \\
\hline Impatient & 0 & 0.0 & 3 & 5.8 & 49 & 94.2 & 41 & 78.8 & 10 & 19.1 & 1 & 1.9 & 6.275 & .001 \\
\hline Worry about my problems & 14 & 26.9 & 16 & 30.8 & 22 & 42.3 & 18 & 34.6 & 21 & 40.4 & 13 & 25.0 & 1.510 & $.131^{*}$ \\
\hline Calm & 1 & 1.9 & 2 & 3.8 & 49 & 94.2 & 52 & 100 & 0 & 0.0 & 0 & 0.0 & 6.424 & .001 \\
\hline \multicolumn{15}{|l|}{ Concentration } \\
\hline Concentration is excellent & 0 & 0.0 & 4 & 7.7 & 48 & 92.3 & 51 & 98.1 & 1 & 1.9 & 0 & 0.0 & 6.450 & .001 \\
\hline Hard to pay attention & 1 & 1.9 & 2 & 3.8 & 49 & 94.2 & 46 & 88.5 & 6 & 11.5 & 0 & 0.0 & 6.318 & .001 \\
\hline Difficult to think & 1 & 1.9 & 1 & 1.9 & 50 & 96.2 & 46 & 88.5 & 5 & 9.6 & 1 & 1.9 & 6.313 & .001 \\
\hline \multicolumn{15}{|l|}{ Craving } \\
\hline Feeling urge to smoke & 0 & 0.0 & 0 & 0.0 & 52 & 100 & 50 & 96.2 & 1 & 1.9 & 1 & 1.9 & 6.524 & .001 \\
\hline Bothered by desire to smoke & 0 & 0.0 & 0 & 0.0 & 52 & 100 & 52 & 100 & 0 & 0.0 & 0 & 0.0 & 6.408 & .001 \\
\hline Think about smoking & 0 & 0.0 & 1 & 1.9 & 51 & 98.1 & 52 & 100 & 0 & 0.0 & 0 & 0.0 & 6.464 & .001 \\
\hline $\begin{array}{l}\text { Troubled getting smoking } \\
\text { out of mind }\end{array}$ & 1 & 1.9 & 3 & 5.8 & 48 & 92.3 & 50 & 96.2 & 2 & 3.8 & 0 & 0.0 & 6.354 & .001 \\
\hline \multicolumn{15}{|l|}{ Hunger } \\
\hline Food is not appealing to me & 42 & 80.8 & 3 & 5.8 & 7 & 13.4 & 3 & 5.8 & 7 & 13.4 & 42 & 80.8 & 5.589 & .001 \\
\hline Nibble on snacks or sweets & 16 & 30.8 & 7 & 13.4 & 29 & 55.8 & 33 & 63.4 & 3 & 5.8 & 16 & 30.8 & 2.424 & .015 \\
\hline Eating a lot & 43 & 82.8 & 7 & 13.4 & 2 & 3.8 & 5 & 9.6 & 9 & 17.3 & 38 & 73.1 & 6.167 & .001 \\
\hline Feel hungry & 48 & 92.4 & 2 & 3.8 & 3 & 5.8 & 6 & 11.5 & 7 & 13.5 & 39 & 75.0 & 5.950 & .001 \\
\hline Think about food & 43 & 82.8 & 6 & 11.4 & 3 & 5.8 & 2 & 3.8 & 7 & 13.4 & 43 & 82.8 & 6.163 & .001 \\
\hline \multicolumn{15}{|l|}{ Sadness } \\
\hline Upbeat and optimistic & 7 & 13.4 & 8 & 15.4 & 37 & 71.2 & 52 & 100 & 0 & 0.0 & 0 & 0.0 & 6.126 & .001 \\
\hline Sad or depressed & 7 & 13.4 & 4 & 7.7 & 41 & 78.9 & 41 & 78.8 & 11 & 21.2 & 0 & 0.0 & 5.934 & .001 \\
\hline Hopeless or discouraged & 8 & 15.4 & 7 & 13.4 & 37 & 71.2 & 39 & 75.0 & 13 & 25.0 & 0 & 0.0 & 5.754 & .001 \\
\hline Happy & 1 & 1.9 & 2 & 3.8 & 49 & 94.2 & 52 & 100 & 0 & 0.0 & 0 & 0.0 & 6.474 & .001 \\
\hline \multicolumn{15}{|l|}{ Sleep } \\
\hline Restful sleep & 3 & 5.8 & 3 & 5.8 & 46 & 88.4 & 51 & 98.1 & 1 & 1.9 & 0 & 0.0 & 6.232 & .001 \\
\hline Insomnia & 11 & 21.1 & 6 & 11.5 & 35 & 67.4 & 47 & 90.4 & 4 & 7.7 & 1 & 1.9 & 5.538 & .001 \\
\hline Satisfied with my sleep & 4 & 7.7 & 5 & 9.5 & 43 & 82.8 & 52 & 100 & 0 & 0.0 & 0 & 0.0 & 6.215 & .001 \\
\hline Getting enough sleep & 3 & 5.8 & 9 & 17.3 & 40 & 76.9 & 52 & 100 & 0 & 0.0 & 0 & 0.0 & 6.277 & .001 \\
\hline Troubled sleep & 0 & 0.0 & 3 & 5.8 & 49 & 94.2 & 52 & 100 & 0 & 0.0 & 0 & 0.0 & 6.389 & .001 \\
\hline
\end{tabular}

*Not Significant 
About two thirds of studied students (65.4\%) stopped smoking after nine weeks of practicing hypnosis and the percentage of smoked packs of cigarettes/day decreased after implementing the program. The results revealed that smoking $>3$ packs/day and <2-3 packs/day declined to zero after the program while the percentage of smoking $>1-1.5$ packs/day was $21.2 \%$ before compared to $1.9 \%$ after implementing the program , and smoking $5-\leq 1 / 2$ packs/day decreased from $17.3 \%$ to $13.5 \%$ after practicing hypnosis for nine weeks (see Figure 2).

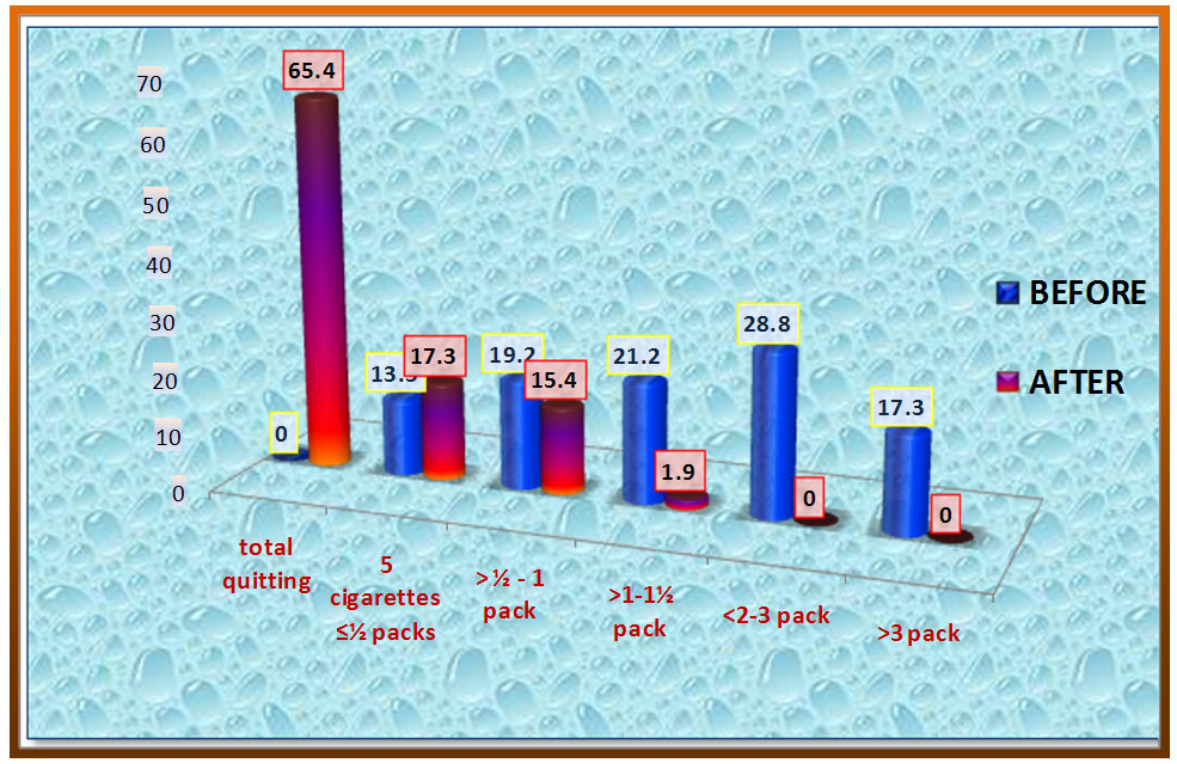

Figure 2: Distribution of studied students in relation to smoked packs before and after intervention

\section{Discussion}

Clinical and research data may not be sufficient to build diagnostic and cessation treatment, so it is necessary to examine the development of withdrawal symptoms among adolescent smokers. ${ }^{[20]}$ Therefore the current study was carried out to examine the effectiveness of hypnotherapy on smoking cessation among secondary school students in Beni-Suef city. The study findings indicated that the rate of male smokers among secondary school students in Beni-Suef city was $52.4 \%$ and $47.6 \%$ was non smokers, these results supported the fact that smoking is a serious problem in Beni-Suef city. This rate was higher than the Prevalence of Mohamed, ${ }^{[21]}$ who found that cigarette smoking among adult males in Egypt according National Household Survey in all 27 Governorates was $30 \%$ for sample over 5000 individuals, and also the $\mathrm{WHO},{ }^{[22]}$ reported that the overall prevalence of daily tobacco smoking in Egypt was 34.6\% among males. While the prevalence was lower (12.9\%) among third-year medical students (male only) for cigarettes in Egypt, ${ }^{[22]}$ and the prevalence of cigarette smoking among male youth aged 13-15 years decreased to reach $5.8 \%$ in Egypt. ${ }^{[2]}$ The current study results has shown a higher smoking rate than the national level, this might be due to the homogeneity of studied students, and no enough health awareness about the drawbacks of smoking.

Regarding number of packs smoked/day, the study results indicated that more than quarter of studied students were smoking <2-3 packs/day, about one fifth of them were smoking $>1-1 \frac{1}{2}$ pack /day and less than two fifth were smoking three and more packs/day. While average of cigarettes smokedday for smokers in Egypt 2005 according to age was 11.2 cigarettes/day for the age $<17$ years and 14.9 cigarettes/day for age 18-24. ${ }^{[20]}$ While in Malaysia the Percentage of the youth smokers who smoked more than 10 cigarettes per day among male students was $41.98 \% .^{[11]}$

Regarding smoking pattern, one third of studied students started smoking since one year while less than quarter started from four years and more, and two quarters of them were living with smoked members, and the most reported reasons for quitting were; to preserve health and money, to be free from smoking, and more than quarter of them never tried to stop smoking in the past while the rest tried once or more, more than half of them stopped smoking for less than one week and very small number quitted for a period of one to three years. These results in accordance with study of many authors who reported that most youth smokers in Canada mentioned that they would like to quit and have tried to quit in the past. ${ }^{[24,25]}$ The immediate precursor of quitting smoking would be an individual's intention to quit; intentions are indications of how hard people are willing to try, of how much effort they are planning to exert, in order to perform a behavior. ${ }^{[26]}$ Empirical research has previously identified that the factors affect with cessation are; having friends who smoke. ${ }^{[27]}$ or intending to quit. ${ }^{[28]}$ It has also 
been suggested that cessation intentions are negatively associated with frequency of smoking. ${ }^{[29]}$ and physical inactivity. Smoking behaviour and beliefs, physical activity and weight, and social influences are associated with intentions to quit smoking.

The studied students ready to change many things in order to stop smoking such as personal habits, lifestyle, and exercise routinely. They mentioned that the family followed by friends considered the support system, and strong willpower and desire are factors were helping them to stop smoking, but they mentioned many fears as failure, mood changes, poor self esteem, or loss of control. Most of them were dealing with stressors through prayers while only $3.8 \%$ were using hypnosis as a method of relieving stress. On the same line U.S. Department of Health and Human Services, ${ }^{[30]}$ highlighted that adolescents and young adults are very susceptible to social influences. If they see tobacco use as a normal behavior because their friends or family members use tobacco, young people are more likely to try tobacco themselves, several factors relating to the students' environments were also associated with current smoking among high school students in Wisconsin, including parental smoking, friend smoking and household smoking rules. Similarly Robinson et al. ${ }^{[31]}$ added that Peer influence is paramount during these life stages, and young people with greater numbers of peers who smoke are more likely to begin to smoke themselves, and Metzger et al. ${ }^{[32]}$ stated that those who have fewer pro-social bonds to conventional institutions, such as school or places of worship, are also more likely to use tobacco.

These relationships are not surprising, as youth typically engage in behaviors they see friends or family engage in on a daily basis-perceiving such behaviors as acceptable. Peer selection or peer influence is still one of the strongest determinants of adolescent smoking so having close friends who smoke is very important to youth smoking cessation. ${ }^{[33]}$

The current study findings illustrated that, about two third of studied students stopped smoking after nine weeks of practicing hypnosis and the percentage of smoked packs of cigarettes/day decreased after practicing hypnosis for nine weeks. These results supported by Rockville, ${ }^{[34]}$ who stated that effective programs are available and have demonstrated success in reducing youth smoking, through adequate dissemination and sustainability of these successful approaches, also school-based policies and programs are effective in reducing the initiation, prevalence, and intensity of smoking among youth and young adults. Moreover Barnes et al. ${ }^{[17]}$ added that hypnotherapy result in higher quit rates compared to no intervention or brief advice.

The present study results also revealed that there is an improvement in all withdrawal symptoms (anger, anxiety, concentration, craving, hunger, sadness, and sleep) after the program, and the results showed statistically significant dif-

Published by Sciedu Press ferences regarding all items of smoking withdrawal index before and after intervention except one sub item of anxiety (worry about my problems), but the percentage of studied students who were worry about their problems before intervention decreased after intervention. In this respect Dickson-Spillmann et al. ${ }^{[35]}$ stated that the hypnosis group members showed a lower withdrawal symptoms score than before intervention as assessed at the two-week follow-up. On the same line Bailey et al. ${ }^{[20]}$ revealed that forty-seven adolescent smokers completed nicotine withdrawal symptoms measures during 10 weeks of cessation treatment. There was a reduction in teen smokers' cravings to smoke and levels of anxiety over the course of treatment; but none of the other symptoms were significantly different over time. While other studies found that ratings of the severity of craving and anxiety decreased over time, but there were no significant changes in the other symptoms over time. Others have reported a decrease in craving and/or withdrawal symptoms over time in smoking cessation trials targeting adolescent smokers. ${ }^{[36]}$ This lack of change over time could be due to the fact that the other nicotine withdrawal symptoms were low, even during the initial weeks of treatment, or the studied adolescents might not interested with intervention program, or not followed all instructions from the hypnotherapist.

The current results clarified that the number of smoked packs/day decreased with time of practicing hypnosis. Similar success rates also occurred in group single-session hypnosis, using self-hypnosis resulted in $22 \%$ of 226 smokers remaining smoke-free. ${ }^{[37]}$ Also Klager ${ }^{[38]}$ added that hypnosis, which incorporates relaxation, imagery and positive suggestion, has been reported to have a success rate as high at $90 \%$. A clinical hypnosis study at the College of Medicine at Texas A\&M University had an $81 \%$ success rate in the three-session hypnosis group, with a $48 \%$ success rate at 12 months post-treatment. ${ }^{[39]}$ This supported by Szudy and Vardigan, ${ }^{[1]}$ they found that, imagery and self-hypnosis have been as effective as other behavioral and psychological approaches. The techniques were even more effective in smokers who found them pleasant. Hypnosis is not the can't-miss solution many advertisements claim it to be, but it does have a decent track record.

On the same line a consecutive series of 226 smokers referred for the smoking cessation program were treated with a single-session habit restructuring intervention involving self-hypnosis. They were then followed up for 2 years. Total abstinence from smoking after the intervention was the criterion for successful outcome, fifty-two percent of the study group stopped smoking 1 week after the intervention; $23 \%$ maintained their abstinence for 2 years. While a review of 9 trials did not find efficacy for smoking cessation. ${ }^{[18]}$

The abstinence rates resulting from our trial are comparable, despite figuring at the lower end, to other studies of a single session of group hypnosis $\left(18.5 \%-25 \%\right.$ abstinence). ${ }^{[37]}$ 
Thousands of people have found hypnosis to be an effective way to stop smoking, hypnosis has a high success rate. Literally, $95 \%$ of people stop in one session. ${ }^{[1]}$

These differences might be explained by our studied students had strong quit intentions, experiencing social support, had contact with the researcher at follow up period; they were meeting once at least every week and contact by phone every day to ensure following instructions of practicing hypnosis, or receiving suggestions in a relaxed state and also they were very interested to the hypnosis.

\section{Conclusion}

The study findings indicated that the smoking rate among secondary school students in Beni-Suef city was $52.4 \%$; hypnotherapy has a therapeutic effect in achieving a high rate of smoking cessation among secondary school students, about two third of studied students (65.4\%) stopped smoking after nine weeks of practicing hypnosis and the percentage of smoked packs of cigarettes/day decreased after implementing the program. The family followed by friends considered the support system, also strong willpower and desire are factors were helping students to stop smoking.

\section{Recommendations}

- Community and school education programs should include sessions on quitting smoking.

- Implementing school-based interventions in combination with antitobacco mass media campaigns.

- Modifies the adolescents' environment to support tobacco free social norms.

- A health systems approach that focuses on promoting and integrating clinical best practices (behavioral and pharmacological) which help tobacco-dependent consumers increase their chance of quitting successfully.

- Creates a negative image of smoking through promoting efforts to stop tobacco use and warning labels with pictures.

\section{Conflicts of Interest Disclosure}

The author declares that there is no conflict of interest statement.

\section{References}

[1] Szudy \& Vardigan, B. Smoking: Ways to Quit for Good Health Day. 2014.

[2] World Health Organization. Global adult tobacco survey: Egypt country report 2009. Regional Office for the Eastern Mediterranean. WHO global report: Mortality attributable to tobacco. Geneva, Switzerland: WHO Press; 2013.

[3] World Bank. Report on the global tobacco epidemic, implementing smoke-free environments. World Health Organization, Geneva. 2009.

[4] Centers for Disease Control and Prevention. Office of Smoking and Health for chronic disease prevention and health promotion, State Tobacco Activities Tracking and Evaluation (STATE): A Report of the Surgeon General. Atlanta, GA: U.S. Department of Health and Human Services, Public Health Service. 2012.

[5] Regina, M. \& Benjamin, M. D. A Report of the Surgeon General Preventing Tobacco Use among youth and Young People: Atlanta, GA: U.S. Department of Health and Human Services. Centers for disease control and prevention, office on smoking and health. 2012.

[6] The American School of Hypnosis. CLINICAL HYPNOSIS, Training Manual From A - Z. 2005.

[7] Lynn, S. J., Green, J. P., Accardi, M., Cleere, C. Hypnosis and smoking cessation: the state of the science. American Journal of Clinical Hypnosis. 2010; 52: 177-81. PMID:20187336 http://dx.doi.o $\mathrm{rg} / 10.1080 / 00029157.2010 .10401717$

[8] Handel DL. Follow-up review of the success rates of hypnosis. Commentary. American Journal of Clinical Hypnosis. 2010; 52: 1735. PMID:20187335 http://dx.doi.org/10.1080/00029157. 2010.10401716

[9] Chaney, S. E, FNP-C., FAANP \& Sheriff, S. Evidence-based treatments for smoking cessation, Lippincott Williams \& Wilkins, J. of Nurse Practitioner. 2012; 37(4): 25-39.

[10] American Holistic Nurses Association. AHNA/ANA Holistic Nursing: Scope and Standards of Practice. 2013; 28-99.
[11] Naing, N., Ahmad, Z., Musa, R., et al. TOBACCO INDUCED DISEASES, Society Factors Related to Smoking Habits of Male Adolescents, Department of Community Medicine, School of Medical Sciences, Malaysia, med.sci. J. 2004; 2(3): 133-140.

[12] National Survey on Drug Use and Health. Understanding and improving health, tobacco use. 2010; 1: 27-29.

[13] Douglas. Preventing Tobacco Use Among Young People a Report of the Surgeon General, Office Smoking Health, department of health and human services, Rockville, Maryland. 2011.

[14] Centers for Disease Control and Prevention. Best practices for comprehensive tobacco control programs. Atlanta, GA: US Department of Health and Human Services, Office on Smoking and Health. 2007.

[15] McKINIEY Health Center. Smoking Cessation Questionnaire, the University of Illinois at Urbana-Champaign. 2002.

[16] Wisconsin Smoking Withdrawal Scale. UW-CTRI Measures and Scales, University of Wisconsin, 2014: center for tobacco research and intervention. 1999.

[17] Barnes, J., Dong, C. Y, McRobbie, H., Walker, N., Mehta, M. Stead, L. F. Hypnotherapy for smoking cessation (Review), Cochrane Collaboration and published in The Cochrane Library by JohnWiley \& Sons, Ltd. 2010; 10.

[18] Abbot, N. C, Stead, L. F, White, A. R, Barnes, J. \& Ernst, E. Hypnotherapy for smoking cessation. Cochrane Database Syst Rev; (2): CD001008. At Scott P Marlow RRT and James K Stoller MD MSc FAARC, 2003, Smoking Cessation.

[19] Spiegel, D., Frischholz, E. J., Fleiss, J. L., Spiegel, H. Predictors of smoking abstinence following a single-session restructuring intervention with self- hypnosis. Department of Psychiatry and Behavioral Sciences, Stanford University School of Medicine, CA. Am J Psychiatry. 1993 Jul; 150(7): 1090-7. PMID:8317582

[20] Baileya, R. S., Harrisona, C .T., Jefferya, C. J., et al. Withdrawal symptoms over time among adolescents in a smoking cessation intervention: Do symptoms vary by level of nicotine dependence? Addict. Behav. J. 2010; 34(12): 1017-1022. PMID:19647373 http: //dx.doi.org/10.1016/j.addbeh.2009.06.014 
[21] Mohamed, M. K. Tobacco Burden in Egypt and Efforts for Control and Prevention: Global Support Needs in Developing Countries, Ain Shams University, Abbasyia, Cairo, Egypt, Egyptian Smoking Prevention Research Institute (ESPRI), Funded by U.S. NIH (Fogarty International Center), Interagency Committee on Smoking and health (ICSH), Meeting on The Global tobacco Epidemic. 2005; 5667.

[22] World Health Organisation. MPOWER: A policy package to reverse the tobacco epidemic. WHO Library Cataloguing-in-Publication Data. Geneva, Switzerland: WHO Press; 2008.

[23] WHO. Tobacco Free Initiative (TFI), GATS (Global Adult Tobacco Survey): Egypt, surveillance and monitoring. 2014.

[24] Oksuz, E., Mutlu, E. T., Malhan, S. Characteristics of daily and occasional smoking among youths. Public Health J. 2007; 121(5): 349-356. PMID:17337284 http://dx.doi.org/10.10 $16 / \mathrm{j} \cdot$ puhe .2006 .12 .007

[25] Leatherdale, S. T., McDonald, P. W. Are the recommended stage taxonomies for the stages of youth smoking onset consistent with youth's perceptions of their smoking status? Canadian Journal of Public Health. 2006; 97(4): 316-319. PMID:16967753

[26] Leatherdale, S.T. Addictive Behaviors, Department of Public Health Sciences, University of Toronto, Canada Population Health Research Group, University of Waterloo, Canada, Addictive Behaviors J. 2008; 30(8): 217-223.

[27] Balch, G. I., Tworek, C., Barker, D. C., et al. Opportunities for youth smoking cessation: Findings from a national focus group study. Nicotine \& Tobacco Research J. 2004; 6: 9-17. PMID:14982683 http://dx.doi.org/10.1080/1462200310001650812

[28] Vuckovic, N., Polen, M. R., Hollis, J. F. The problem is getting us to stop. What teens say about smoking cessation? Preventive Medicine J. 2003; 37: 209-218. http://dx.doi.org/10.1016/S0091-7 435 (03) 00115-4

[29] Grimshaw, G.S., Blackburn, C., Andrews, K., Grimshaw, C., Vinoradova, Y., et al. Patterns of smoking, quit attempts and services for a cohort of 15- to 19-year-olds. Child, Care, Health and Development J. 2003; 29(6): 457-464. http://dx.doi.org/10.1046/j $.1365-2214.2003 .00365 . \mathrm{x}$

[30] U.S. Department of Health and Human Services. The Health Consequences of Smoking: A Report of the Surgeon General. Atlanta (GA): U.S. Department of Health and Human Services, Centers for Disease Control and Prevention, National Center for Chronic
Disease Prevention and Health Promotion, Office on Smoking and Health. 2012.

[31] Robinson, L. A., Murray, D. M., Alfano, C. M., et al. Ethnic differences in predictors of adolescent smoking onset and escalation: a longitudinal study from 7 th to 12 th grade. Nicotine \& Tobacco Research J., 2006; 8(2): 297-307.

[32] Metzger, A., Dawes, N., Mermelstein, R. \& Wakschlag L. Longitudinal modeling of adolescents' activity involvement, problem peer associations, and youth smoking. Journal of Applied Developmental Psychology. 2011; 32(1): 1-9. PMID:21603061 http: //dx.doi.org/10.1016/j.appdev.2010.09.005

[33] Clark, P. I, Schooley, M. W., Pierce, B., Schulman, J., Hartman, A. M, Schmitt, C. L. Impact of home smoking rules on smoking patterns among adolescents and young adults. J. Prev Chronic Dis. Apr 2006; 3(2): A41.

[34] Rockville, M. D. Treating tobacco use and dependence: Agency for Healthcare Research Quality; United States Department of Health and Human Services (USDHHS]. 2012.

[35] Dickson-Spillmann, M., Haug, S., \& Schaub M P. Group hypnosis vs. relaxation for smoking cessation in adults: a cluster-randomized controlled trial, thesis, BMC Public Health. 2013; 13: 1227.

[36] Killen, J. D, Robinson, T. N, Ammerman, S. Randomized clinical trial of the efficacy of buproprion combined with nicotine patch in the treatment of adolescent smokers. Journal of Consulting and Clinical Psychology. 2004; 72(40): 729-735. PMID:15301658 http: //dx.doi.org/10.1037/0022-006X.72.4.729

[37] Ahijevych, K., Yerardi, R. Nedilsky, N. Descriptive outcomes of the American Lung Association of Ohio hypnotherapy smoking cessation program. International Journal of Clinical and Experimental Hypnosis. 2000; 48(4): 374-87. PMID:11011498 http://dx.doi .org/10.1080/00207140008410367

[38] Elkins, G., Marcus, J., Bates, J., Hasan Rajab, M., Cook, T. Intensive hypnotherapy for smoking cessation: a prospective study. Int J Clin Exp Hypn. 2006; 54(3): 303-315. PMID:16766441 http: //dx.doi.org/10.1080/00207140600689512

[39] Elkins, G. R \& Rajab, M. H. Clinical hypnosis for smoking cessation: Preliminary results of a three-session intervention. The International Journal of Clinical and Experimental Hypnosis. Texas A\&M University System Health Science Center College of Medicine, USA. 2004 Jan; 52(1): 73-81.

[40] Carrie, P. Quit smoking with hypnotherapy, quit smoking in 2 hours with a 12 month guarantee, Perth Hypnosis Centre. 2005. 